all, or any of their characteristics, an analogy to the exanthemata.

My own opinion is, that they have a strong resemblance in many essential features.

As to the first point-their contagion-notwithstanding the doubts of a few, it may be assumed as proved, that typhus is a contagious disease, and that even enteric fever may, under certain circumstances, be communicated. In this respect there is, therefore, an aualogy between the continued and the eruptive fevers.

The second point--that they are limited to a single attack during life-is, perhaps, less easily determined; but the evidence adduced in the affirmative by trustworthy observers is such as to render it more than probable, that those who have once had either form may be considered safe from another attack of the same fever. In some instances, individuals have been admitted into the hospital who had previously passed through an attack of enteric fever; and on close examination of the patient, and reference to the history of the first attack recorded in the journals, it has been discovered that all the characters of the former fever presented themselves; but such cases are, on the whole, few in number, and form an exception to the general law, just as we know that during the prevalence of other epidemics, (small-pox, measles, or scarlet fever, for example, the same person is occasionally, though rarely, attacked a second time.

The evidence of Chomel, on this point, is worthy of attention. He states that, notwithstanding the care with which patients affected with enteric fever are interrogated, on entering the hospital, on this point,-and they amounted to $130,-$ no one gave such a reply as would lead to the inference that there had been a previous attack; indeed, the almost invariable statement was, that it was the first time they had been ill and, he adds, that the result of the facts hitherto collected tend to prove that enteric fever, in ordinary circumstances, affects the same individual only once.*

Dr. Lombard, of Geneva, in his observations on the difference between British and Continental typhus, mentions that in one remarkable point of view both agree-viz, that no one is known, or at least is very rarely known, to have the eruptive typhus twice. "With us (in Geneva) such instances are scarcely ever met with; and I am informed," he goes on to state, "that with you" (that is, in this country) "a person once attacked with typhus attended with the measles-like eruption, may safely calculate upon immunity from the disease for the future." +

The facts also adduced by Drs. Barker and Cheyne give great strength to this view. They state that at the Corkstreet Hospital only one physician and the apothecary had an attack of fever; but then, most of the physicians had laboured under that disease on some occasion previons to the epidemic.

Similar testimony is given by Dr. Davidson, in his Essay on Fever. He tells us that almost all the clerks and nurses of the Glasgow Fever Hospital, for the last six or seven years, have had typhus characterized by the eruption, "and not one of them, so far as we have been able to learn, have ever had it since, while almost all of them consider themselves now perfectly secure against a second attack, although constantly exposed to the effluvia arising from fever patients."

The idea has been suggested by some physicians-and it is a plausible one-that contagious typhus, like the exanthematous fevers, if accompanied by its characteristic eruption, produces in its course some changes in the system, by which an individual having once undergone the disease is, as a general rule, secured against a second attack. This theory has been argued by Dr. Penny, of Glasgow, in his elaborate paper on Fever. + He thinks that in those instances of second attacks which form exceptions to the general rule, the fever appears in a mild and modified form, the crisis taking place on the seventh, ninth, or eleventh day. He has come to these conclusions, he adds, after careful observation of 4000 cases.

Others, again-Hildenbrand amongst the number-suggest that the miasm of typhus, after having produced the fever, destroys, almost always for a certain time, the susceptibility to a similar contagion, rarely, however, for the whole period of life, as small.pox and measles do. But whether the explana. tions given be received or not, the question is full of interest in many points of view, and well worthy of further investigation.

The third point of analogy is the exanthema or rash. The distinctive characters of the rash peculiar to each form of fever has been already cursorily brought under your notice - the pro-

* Chomel, vol. i., pp. 321, 333, and 309.

† Dublin Journal, vol, x., p. 22.

‡ Edinburgh Medical Journal, vol, xiv., p. 87. portion of cases, as we shall afterwards see, in which it appears being so large, that the exceptions may be said to prove the rale. In the one-the lenticular rose spot, the period of the fever when it appears, its continuing a certain number of days and then vanishing, to be succeeded by a fresh crop, to go through the same changes; while in that of the other-typhus-the darker, morbillous, or mulberry eruption, differs in one im. portant particular, that it is persistent so long as the fever lasts.

The occurrence of these two peculiar eruptions, dissimilar as in some respects they are, shows a marked analogy in both to the exanthematous fevers. The exceptional cases-those in which the eruption is absent-cannot be urged against this view, since in one of the eruptive fevers, the scarlet fever, the rash is occasionally absent, though in other respects the whole phenomena of the disease are manifest. Even in measles, the efflorescence is occasionally either absent, or so evanescent or ill developed, as often to lead to great difficulty and doubt in the diagnosis.

Besides these three points, in which the analogy is well marked, I may allude to the duration of the two forms as constituting a point of resemblance. We know that in typhus, if uncomplicated, the symptoms decline about the fifteenth day; the duration of enteric fever is much more protracted, being generally from twenty to thirty days, often much beyond. The ercptive fevers, when not complicated, run a pretty remlar course, both as to the time of the appearance and decline of their distinctive rash (which differs in each), so that in their duration, as well as in the several particulars thus brieffy adverted to, there is, to say the least, a great resem. blance between the two forms of continued, and the exan. thematous or eruptive fevers.

\section{ON THE GREAT IMPORTANCE OF EARLY DIAGNOSIS AND TREATMENT FOR STONE IN THE BLADDER.}

By HENRY THOMPSON, F.R.C.S., ASSISTANT-SUZGEON TO UNIVERSXTY COLLEGE HOSPITAL, BTC. ETC.

There are few amongst the maladies which afflict humanity that are generally regarded, both by the patient and the sur. geon, as fraught with graver import, than stone in the bladder. There are no cases that are observed in our hospitals with greater interest, and there are none in which the surgical procedures commonly adopted for their relief involve greater responsibility on the part of the operator, or are more attractive to the surgical student, from the momentous importance which attaches to them. Grave in the highest degree, however, as, by universal consent, is the situation of the adult patient with a calculus of considerable size in his bladder, it is a fact worthy to be well and deeply considered, that the existence of such a calculus is, in the great majority of cases, a matter wholly preventible; and that, within certain limits, it must be regarded as a result which, by the exercise of a moderate amount of intelligence and care, may be rendered extremely uncommon. It is so, because the presence of a vesical calculus may almost always be ascertained in an early stage; and because its destruction in that stage is an operation which, with a fair amount of skill, may generally be accomplished with certainty, and with safety to the patient. The first indication-namely, to prevent the formation of a stone of moderate or average size -is insured by an intelligent appreciation of the early signs which it produces; in other words, by a diagnosis of its exist ence while it is yet quite small. The second indication may generally be fulfilled by crushing it in that stage.

In reference to the subject of counteracting a constitutional tendency to calculous formation, it is not within the limit of this article to enter on the important and fertile theme of medical treatment for its prevention. The question here is only that of early diagnosis, and the treatment which is desirable when the existence of a small stone is verified. Before entering on this, I shall cite briefly a few cases in illustration of the proposition, that under these circumstances the cure of the complaint is safe and simple. 
CASE 1.-A gentleman, aged thirty-nine, while staying in Malta on his return from India, was recommended to consult me by my friend Mr. Filliter, then in practice there. He had suffered for some months from irritability of the bladder and severe pain after passing urine, with occasional pains in the back and loins. There had been no bleeding observed, and no pain in the glans penis. Instruments had been passed in India; no stricture was discovered. The general health was somewhat impaired. I. saw him first on October 16th, 1857, and after investigating his case suspected the presence of stone. It was agreed that he should be sounded in a few days. The urine exhibited on two occasions the presence of blood, although in quantities only to be appreciated by the microscope.

Oct. 24th. - The pelvis being well elevated, I introduced a lithotrite; and, after some little searching, caught a small stone, and effectually crushed it. $\mathrm{He}$ was in bed, and re. mained so during the day.

25th and 26th.-Irritability increased; several fragments came away, which he carefully preserved. From their appearance $I$ was inclined to think there must have been two small calculi.

29th. - Much better. I introduced the lithotrite, and found one fragment, which was crushed.

Nov. 1st.-More débris has been passed.

15th.-Perfectly free from all symptoms.

CASE 2.-A gentleman, aged thirty-one years, was brought to consult me by my friend, $\mathrm{Mr}$. Tweed, of Brook-street, on Sept. 8th, 1857. During the last eighteen months he has suffered severely from urinary derangement; and for tifteen months there have been fistulæ in the perinæum. In France, where he resided during the summer, he was advised to pass all his urine by catheter, in order to give them a chance of closing. He did so, and with the desired effect. They have since, how. ever, reopened, and they exist now. On examination, no stricture nor any disease of the prostate is detected, and there appears no reason to believe that either has existed. I then introduced a sound, and discovered a small calculus.

The next day, Sept. 9th, he paid me a second visit, when I introduced a lithotrite, and crushed at once a small caleulus, about the size of a bean. He walked home to his house in Brook-street. During the week he passed débris, which were all phosphatic.

Sept. 16th.-I introduced a lithotrite, but could find nothing in the bladder. Symptoms continue, although diminished in intensity.

22nd.- Again introduced the lithotrite, found a small piece, and crushed it. The débris passed next day.

Oct. lst.- He left town perfectly free from symptoms; but he passed a few small fragments during the month.

After this he completely recovered, and enjoyed excellent health for more than a year. He had, however, wholly neglected to adopt a system of diet and medicine which we were anxious he should follow perseveringly, as there was reason to believe a constitutional tendency to form phosphatic matter existed, the urine being still always alkaline and phosphatic.

In May, 1859, he reappeared with a calculus of considerable size, and in completely broken health, having suffered severely upwards of a year. After due preparation, I attacked th calculus, and successfully removed it after six applications of the lithotrite. He is now enjoying excellent health. The fact only is mentioned here as the former part of the case illustrates the subject of this paper.

CASE 3.-A gentleman, aged forty-five, was under my care in September, 1858, for stricture of the urethra, which was successfully treated by dilatation in the ordinary manner. Some symptoms of urinary derangement remained after No. 11 sound had been reached, which evidently demanded further investigation. Accordingly, I introduced a lithotrite, and, after some searching, discovered a calculus, measuring three eighths of an inch, according to the scale of the instrument. I crushed it at once at the patient's rooms.

Next day, Oct. 12th, some fragments of urate of soda passed, and débris followed on succeeding days.

Oct. 19th.-Again crushed two or three fragments. After three days, no more debris passed, and the symptoms disappeared. A week afterwards the patient was carefully sounded, but nothing was discovered. He has been perfectly free ever since. The calculus was urate of soda.

CASE 4.-H. A-_, aged thirty-six, and supposed to be the subject of stricture, was sent to me as an out-patient at University College Hospital, Feb. 25th, 1859, with some symptoms, not very urgent, of urinary derangement. I passed an instrument, and found that there was no contraction, or other cause for his complaints in the urethra or prostate, and then introduced a sound into the bladder, and soon discovered a small tone. His urine was examined, found healthy, but depositing octahedra of oxalate of lime. He was directed to come at my next visit, March lst, when I introduced a lithotrite, and in the presence of a number of pupils, without any pain worth mentioning as he said, and certainly withont any expression of it, I crushed at once a calculus about the size of a nut. It is almost unnecessary to say that he had no chloroform. There were no traces of bleeding, and no signs of irritation following. Consequently, after an hour's rest, I desired him to walk slowly, not to ride, to Camden-town, where he lived. Two succeeding crushings followed-one on the 6 th, the other on the 9 th of March, small débris passing easily after each sitting. The calculus was oxalate of lime. Being perfectly relieved of all his symptoms, he returned to his work at Pickford's, as night-porter, on the 16th of March, being the fifteenth day from his first sitting. He has continued at work ever since and is perfectly free from all his old symptoms, having called at the hospital during the last month to tell me so.

It is by no means uncommon to find small calculi forming in connexion with stricture of the urethra. These may be spontaneously voided after dilatation has been fully completed, or their removal may be accomplished by some mechanical aid from the surgeon. Such occurrences are to be looked for when symptoms persist after the urethral obstruction has been removed. By so doing we may be the means of freeing the patient from the presence of a small concretion, and may probably save him from the grave consequences of serious calculous formation hereafter. I have several such small calculi, which have been removed or expelled from different patients in such circumstances. Of these, the following case is an interesting example :-

A gentleman was recently brought to me with an extremely obstinate stricture, by Mr. Davis, of Hanley, Staffordshire, who staid with him during the treatment. This consisted, at first, in introducing a very slender silver catheter, which, after some time and trouble, I succeeded in accomplishing; in tying it in, and subsequently replacing it by gum catheters, also tied in, until a tolerable size had been reached. During the progress, a symptom or two occurred, which led us to suspect a small cal. culus, and on one occasion I was satisfied that I had felt it with the gum catheter. Next day I engaged it in the eye of the catheter, and drew it along the urethra as far as to the stric. ture, beyond which it could not be made to pass. Twenty-four hours more of tying-in dilated this still further, and next day it was again caught, and ultimately came away. It was about the size of a grain of wheat, but longer. Had it not been removed in this early stage, it would undoubtedly have formed the nucleus of a larger calculus, and it is on this account mentioned here as another illustration of the principle laid down.

It appears to me to be desirable also, in the cases of children, to ascertain, if possible, at an early period the existence of calculus. A very small one, having made its descent from the kidney to the bladder, instantly gives rise to symptoms in young subjects; and before it reaches the size of an apple-pip, is often the cause of great distress. Many, doubtless, have seen the operation of lateral lithotomy performed for a concretion even smaller than that. In such a case, I prefer a small lithotrite, of which the diameter is between 5 and 6 of the ordinary catheter scale, made for me by Mr. Coxeter; it does not require a screw, which simplifies the instrument greatly, the power applied by simple pressure of the hand being amply sufficient for such purposes. With this the stone is seized, and if the scale indicates that its size is very small, it may be crushed at once; if it is larger than a pea, $I$ think it is better to cut, as the expulsion of any but small fragments is attended with much difficulty, while the cutting operation is generally as happy in its results in children, as it is hazardous in the adult. After lithotrity in them, the efforts of the bladder are very powerful, while the urethra is so narrow and delicate, that, except in the smallest calculi, the removal of fragments may occasion much difficulty, and then, no doubt, lithotomy, especially the median, would be both simpler and safer. The great object, however, should be to detect the calculus when it is, as all are at first, extremely small.

The application of the principle is easy; a case which occurred about a month ago, at Tniversity College Hospital, will illustrate this:-

A little boy, aged three years and a half, was brought to me at the out-patients' room on the 30 th of November, 1859 , with symptoms of urinary derangement, said to be of four months' duration. He had been under medical treatment two months without benefit. Suspecting calculus, he was put under chloro- 
form. I sounded him, and found one, which, from the bladder having expelled its contents, appeared to be small. He was desired to come again in a week's time, intending, if it proved to be so, to crush it.

Dec. 9th. - Under chloroform, I introduced the small lithotrite, and caught a stone which measured half an inch in diameter. I decided at once to make no attempts to crush it, but to cut him, which I did on the 14 th by the median operation, removing a stone the size of a marble. He made a rapid recovery, and left the hospital on the 30th.

Had the stone been half the size, I conld easily have reduced it to powder with the small lithotrite-the essential proceeding in the case of children-its flat blades, not fenestrated, being especially adapted for reducing fragments to a state of powder, which passes easily.

It is important to inquire what are the signs which indicate the existence of calculus in that form of small concretion which it must always assume in the early stage, and which in most cases it maintains for a considerable period of time during the early history of its progress. The ordinary and most obvious symptoms of stone are usually regarded as the following:Pain at the close of the act of passing urine; pain in the glans penis; pain increased by sudden movements of the body; sudden stopping of the stream of urine during its flow, and its reappearance after change of position in the body; occusionally blood in the urine after exercise. In addition to these are frequent wants to micturate-a symptom met with more or less in all complaints of the urinary organs. In most cases, also, there is some change in the urine itself, produced by organic or inorganic additions to the normal elements. In elderly subjects with enlarged prostate, the urine sometimes affords more marked evidence than the subjective symptoms, which may be masked by the condition of the prostate, or confounded with the symptoms arising therefrom. Amongst the numerous patients who complain chiefly of irritability of bladder, and some pains associated with micturition, we may rely upon it that in nineteen out of twenty there is some material and recognisable cause. There is either inflammation of some portion of the track from the kidney to the urethra inclusive, the locality of which may be determined; or there is obstruction, the precise nature of which can be ascertained; or there is some adventitious growth or deposit, or some organic change taking place in some part, and presenting symptoms or imparting characters to the urine which are almost unmistakable. Now, in the early stage of vesical calculus, its discovery is due at first to the observation of the negative rather than of the positive signs. Frequent and painful micturition being complained of, the alsence of inflammation of the urethra or bladder, or at all events its non-existence as a primary state, is ascertained by reference to the present condition and to the history; while catheterism determines the absence of obstruction; and urinary examination, in connexion with the general symptoms, indicates whether or no organic disease exists. Having thus excluded all these causes, the occurrence of marked pain at the end of micturition, the occasional appearance of a little blood in the urine, although only microscopic, with the persistence of some crystalline deposit and of some pus, however slight in amount, in the urine, should awaken a strong suspicion of the existence of a calculus. A careful examination by the microscope of the urine passed on several successive days should generally be made, always in cases of obscurity, since the indications just alluded to, and which are so obtained, are often extremely valuable. If, in addition to these signs, there is any distinct history of recent pain, more or less acute, in the course of either ureter, and lasting for a few hours, the suspicion will be greatly streagthened. Whether this lastnamed sign have been present or not, a patient in the circumstances above described ought to be sounded. In the operation of searching for the calculus itself, it is necessary to remember that a small stone is less easy to detect than one of ordinary size, and that it is as difficult sometimes to miss the one as to find the other. In order to sound efficiently, but especially in a case where there is reason to believe that the stone is small, a sound of appropriate form is necessary. It is barely possible to search a bladder thoroughly with a sound curved like the ordinary catheter, inasmuch as every part of the cavity cannot be explored by such an instrument. The sound should have a very short and well-curved extremity, which can be rotated in the bladder without difficulty, and without causing pain to the patient, so that the floor of the bladder behind the prostate can be searched as freely as any other part by turning the short beak downwards. It is manifestly impossible thus to explore if the curved portion of the sound be long, and the defects of such an instrument are still more obvious when the prostate is materially enlarged. Next, the sound should be hollow, so that water can be injected through it into the bladder, or flow outwards from it, in order that the surgeon may possess the advantage of sounding while the bladder is in various degrees of distension, indeed in every intermediate condition between full and empty. The patient should lie on his back, with the pelvis elevated from four to six inches above the shoulders. If bothing is found, supposing the search to have commenced with about ten ounces of fluid in the bladder, about half may be allowed to run off as the searching continues. At this point, if nothing is discovered, the patient may be carefully raised into the upright position, and the bladder then be permitted to empty itself through the sound, which being gently moved will scarcely fail to detect a very small calculus, if such a one be present, since it is almost certain to be brought down against the sound with the last portion of the outflowing current.

Perhaps the best situation for the eye of a hollow sound is on the convex part of the curve, and not at its extremity, which being thus left solid and heavy affords more certain in. dication to the operator than if hollowed, and consequently feeling light in the hand. (See engraving.) The material ad.

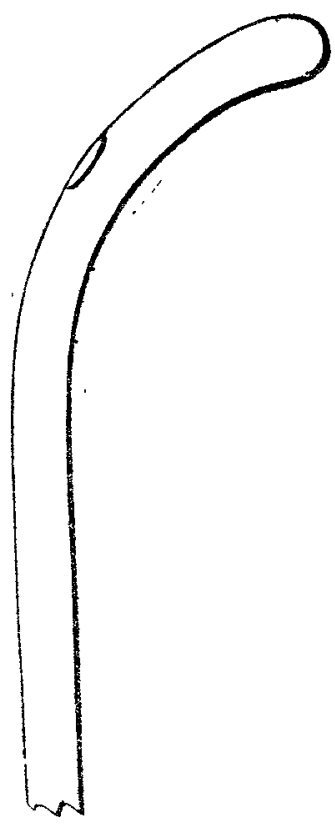

Extremity of sound of natural size. The instrument is hollow throughout up to the opening seen at the bend, beyond which it is solid.

vantage gained by employing the hollow sound is, that the introduction of a single instrument only, suffices for the whole process of emptying, injecting, and searching the bladder. The lithotrite itself answers very well as a sound; and, if it possesses a small channel through it so as to admit the flow of fluid, is equal to the instrument just described, with the single drawback of its being less rounded in its surface and outline, and thus a little less easily borne by the patient. On the other hand, it enables the operator to crush a small calculus at the same time, without further manipulation, if thought desirable. It is my firm belief that the early diagnosis of calculus might, in the great majority of cases, be made without diff. culty, if suspicious symptoms were more sedulously observed when they first arise, and the necessary examination made when simple means had failed to dispel them. For it may be safely affirmed that there are very few patients indeed who will not seek professional advice against the troubles which arise during the early stages of the formation, these being quite sufficient to awaken their anxious attention. Granting the truth of this proposition, and holding the certainty and safety of lithotrity for small calculi as a universally admitted fact, there inevitably results the following deduction, the import. ance of which it is impossible to over.estimate, namely-

That stone in the bladder-one of the direst of human mala. dies, and in the removal of which one of the most severe and fatal operations is still most commonly performed-may, through the exercise of ordinary intelligence and skill, be deprived of nearly all its severity, and of its danger to life.

I cannot doubt that the time is not very far distant when the gravity of the affection will in this manner be greatly diminished. It will be so in proportion to the increased vigiance which is exercised in practice. Much as our art accom. plishes in the cure of established disease, its value is mot 
apparent, and its applications are really fraught with the highest benefits to humanity, when exercised mainly by way of prevention. Its greatest achievements, and most honourable, are those by which evil has been averted from the frame, not those by which such evil is removed or palliated. My object now is to press upon the attention of my professional brethren the convictions which have been recorded here, and the grounds of which I have endeavoured, briefly and imperfectly, to show both by reason and by practical illustration. If they are correct, the study of calculous diseases offers another example to those already existing of the extreme value, in relation to therapeutics, of all that tends to perfect the art of Diagnosisa principle the truth of which has been demonstrated by almost every improvement which has marked the progress of medicine and surgery during the present century.

Wimpole-street, Jan. 1860.

\section{ON THE CURABILITY OF CANCER.}

\section{BY JAMES ARNOTT, M.D.}

That a "vis medicatrix naturæ" operates in all diseases to which the body is subject, and that this may be generally sufficient to remove them, are, I believe, universally admitted propositions. There is a great difference, however, between diseases in respect to the certainty or facility with which nature alone accomplishes a cure. A catarrh, or boil, may, if not very severe, be confided to her powers exclusively; but very rarely will these be found adequate in consumption or cancer.

The question which we have to consider is, have any means been discovered of supplanting, or aiding, the efforts of nature in the cure of cancer; or is it likely that any such means will be discovered? I shall speak first of internal remedies, or such as may be supposed capable of influencing the constitution of the patient.

Hemlock, arsenic, iodine, mercurr, andis other potent medicines, have at various times, and by various respectable practitioners, been declared to be effectual remedies of cancer, and many narratives of cases have been published in proof of these assertions. I do not say that cancer may not have been cured by some, if not all, of these methods, whether regarded as ad. juvants of nature merely, or as agents independent of her efforts. Judging from the properties of some of these substances, there is nothing very improbable in the assertion. They strongly influence the constitution, and this powerful action may, perhaps, supersede the morbid action constituting cancer, on the principle laid down by Hunter,-that no two powerful morbid actions can coexist in the same body. Other plausible theories may be brought in favour of this opinion. Many years ago when I had the opportunity of witnessing the extraordinary curative effects of large doses of mercury administered in the diseases of India, I was led to the conclusion (which I have expressed in a work on the use of mercury in these diseases), that as a rule every acute inflammatory disease can be arrested by mercurial salivation, if effected before any disorganization has occurred; and, generally speaking, when employed in time, and due discrimination is made, the hazard of the remedy itself is much overbalanced by its curative advantage. But if mercury were given as profusely in those chronic diseases which are generally reckoned incurable, much mischief would be the result. A few cures, perhaps, might be effected, but many patients would be quickly cut off by this potent agent, who might otherwise have a prolonged and comfortable existence, and who might even be cured by the efforts of nature. Such a practice must, therefore, be pronounced rash and unjustifiable. The expesure of a patient to the infection of small-pox might cure him of some other obstinate disease with which he was affliebed, (and we have lately had an interesting illustration of this recorded by Dr. Adams, ) but who wonld dream of making a practice of using so dangerous an expedient ?

We are told in Lady Holland's Memoir of the Rev. Sydney Smith, that he was at one period in his life a dabbler in physic amongst his parishioners; and, perhaps, from there being no regular medical advice easily accessible in the remote district where he then lived, such dabbling may not only have been pardonable, but commendable. Like the medical gardener mentioned by Sir Walter Scott, his "simples" were probably "calamy" and "laudamy," but an unexpected salivation produced by the first of these so alarmed him as to put a stop to his medical career. The reverend gentleman, whose medical exploits have been lately engaging public attention, is made of sterner stuff; he has no such fear of mischief, and he thoroughly understands the advantage that may be obtained by the publication of one apparently successful case from the administra. tion of this hazardous remedy. That mercury may, perhaps, be useful in certain cases of cancer might be admitted, but there is no sufficient proof that the patient whose case has been reported as an instance of cure from its use laboured under this disease, for neither the history of the case, nor the symptoms, were those of cancer.

Remedies applied locally in cancer are generally supposed to be only palliative. The knife and caustic remove cancerous disease only for a time. The principal objection to the knife is the danger of the operation itself proving fatal, for Mr. Paget and other writers have shown that ten per cent. of those operated upon die from it; and the principal objection to canstic is the dreadful and prostrating suffering caused by it. There is no mode as yet known of removing the first of these objections : we have no preventive of pyæmia, of erysipelas, or of sudden death from chloroform. But it is not so as regards the second expedient: we can prevent the pain from caustic by intense or benumbing cold. Granting, for the sake of argument, that cancer is, on all occasions, and in every stage of the disease, a constitutional affection, still as it always, or almost always, proves fatal by the irritation and exhaustion pro* duced by its local effects, if these can be prevented by a safe and painless mode of removal, what must be deemed a close approximation to cure will be accomplished. But this is not the only use of intense cold in cancer. Whether it operates by destroying the vitality of the cancer-cell, by obviating inflammation, or other means, it will, in many cases, either cause the disappearance of the tumour, or reduce it to a torpid or apparently lifeless condition, like a bullet in the flesh; and, while this is being accomplished, it relieves the dreadful pain which so often accompanies the disease. It is much to be regretted that an agent possessing these properties should have suffered in reputation from the unskilful manner in which it has been tno often employed. In cases of open or ulcerated cancer, when the sore cannot be healed, and where it might almost be supposed to act as a safety-valve, or means of eliminating the poison from the blood, we have, in a judicious use of congelation, a powerful repressant of the irritation that would otherwise torture the patient, and rapidly bring his life to a close.

As instances of an imperfect mode of using cold in cancer, I will (paradoxical as it may appear) adduce two published reports of cures said to be effected by it. In these two cases, it might, indeed, have proved effectual; but it certainly wonld not do so in the vast majority of cases if employed in the same manner, and differing so much from that which I have recommended. The first may be found, reported by Mr. Simon, in one of the early volumes of the "Transactions of the Pathological Society;" but as the disease recurred after a year, in another part of the body, (a circumstance, however, proving that it was really cancerous, ) the case is not very satisfactory. The second was published in the Bulletin de Therapeutique of Paris for the 15th of April last. A large tumour, pronounced to be cancerous by Velpeau, Manec, and other surgeons, was completely removed by about twenty applications of a frigorific mixture applied in such a manner as rarely to produce congelation. If it was the cold that operated beneficially on these two occasions, a different explanation of its modus operande must be given from that suggested in the above observations. York-street, Portman-square, Jan. 1860.

Extrophy of THE BLADDER.-The surgical efforts to remedy this repulsive and distressing deformity have hitherto met with the most disastrous failure. Mr. Ayres, of Now York, has, however, managed to successfully treat such a case. It was in the person of a female, aged eighteen, and accompanied by prolapsus uteri. 'To cover the bladder, $\mathbf{M r}$. Ayres took a flap from the upper part of the skin of the abdomen, the base of the flap being immediately above the bladder; this flap he turned down. To obtain a pouch or reservoir for the urine, Mr. Ayres covered the external or bleeding place by a hypogastric flap, with its base below. He adopted remarkable precautions to prevent gangrene, and his success was perfect. A photograph accompanying his brochure gives an excellent view of the deformity. 